\title{
Discovery of tear biomarkers in children with chronic non-infectious anterior uveitis: a pilot study
}

\author{
Sheila T. Angeles-Han ${ }^{1,2^{*}}$, Steven Yeh ${ }^{3}$, Purnima Patel ${ }^{3}$, Duc Duong ${ }^{4}$, Kirsten Jenkins ${ }^{5}$, Kelly A. Rouster-Stevens ${ }^{5,6}$,
} Mekibib Altaye ${ }^{8,2}$, Ndate Fall ${ }^{1,2}$, Sherry Thornton ${ }^{1,2}$, Sampath Prahalad ${ }^{5,6,7}$ and Gary N. Holland ${ }^{9}$

\begin{abstract}
Background: Biomarkers in easily obtained specimens that accurately predict uveitis in children with juvenile idiopathic arthritis (JIA) are needed. Aqueous humor has been studied for biomarkers, but is not routinely available. We evaluated tears from children with chronic anterior uveitis (CAU) for biomarkers reported in aqueous humor. In this pilot study, we used Schirmer strips to collect tears from seven children (nine eyes); three children had JIAassociated uveitis (JIA-U) and four had idiopathic disease (I-CAU). Liquid chromatography-tandem mass spectrometry was used to identify and quantify tear proteins. The Mann-Whitney $U$ test identified differential tear protein expression between children with JIA-U and those with I-CAU.

Results: S100A9, LAP3, TTR, MIF, SCD14, S100A8, and SAA1 were detected in tears of all children; the same cytokines have been reported in aqueous humor of children with JIA-U. Tears from children with JIA-U had higher expression of proteins associated with inflammatory arthritis (SEMA3G, TIMP1, HEXB, ERN1, and SAA1) than tears from those with I-CAU. In addition, we found higher expression of SCD14, S100A8, and SAA1, but lower expression of S100A9, LAP3, TTR, and MIF, in tears from children with JIA-U compared to tears from those with I-CAU.

Conclusions: Tears contain similar cytokine profiles to aqueous humor in children with CAU and may be a clinically useful source of disease biomarkers. Tears from children with JIA-U also contain cytokines associated with inflammatory arthritis; furthermore, differential expression of other tear proteins as well may provide clues to intrinsic differences between JIA-U and I-CAU, despite their similar clinical phenotypes.
\end{abstract}

Keywords: Juvenile idiopathic arthritis, Uveitis, Biomarkers

\section{Background}

Chronic anterior uveitis is the most common extra-articular manifestation of juvenile idiopathic arthritis (JIA), occurring in $20 \%$ of affected children [1-4]. Of note is the fact that, in $10 \%$ of all cases, anterior uveitis develops prior to arthritis [1]. Idiopathic chronic anterior uveitis (I-CAU) and JIA-associated uveitis (JIA-U) have similar clinical phenotypes, although inflammatory arthritis is not present in children with I-CAU. Understanding the underlying pathogenesis of both inflammatory arthritis and uveitis

\footnotetext{
* Correspondence: sheila.angeles-han@cchmc.org

${ }^{1}$ Division of Rheumatology, Cincinnati Children's Hospital Medical Center, 3333 Burnet Avenue, MLC 4010, Cincinnati, OH 45229, USA

2Department of Pediatrics, University of Cincinnati, Cincinnati, $\mathrm{OH}$, USA

Full list of author information is available at the end of the article
}

may have diagnostic and treatment implications in children with JIA.

JIA-U is typically asymptomatic, and routine ophthalmology screening is recommended [5]. Children at highest risk for uveitis are those with oligoarticular and polyarticular rheumatoid factor (RF)-negative JIA, who are $<7$ years old at JIA onset, with $\leq 4$ years duration of JIA, and who are antinuclear antibody (ANA)-positive. These factors are not, however, adequate to stratify risk accurately [6, 7]. Serum and aqueous humor $(\mathrm{AqH})$ have shown differential expression of cytokines and chemokines (e.g., interleukin-29/interferon- $\lambda 1$ [IL-29/IFN- $\lambda 1$ ], transthyretin [TTR]) in children with JIA-U [8-12]; however, the invasive nature of $\mathrm{AqH}$ collection precludes collection from children with JIA but no uveitis and 
from those who are not undergoing eye surgery. Serum also may not accurately reflect ocular inflammation $[8$, 9]. Tears are used in biomarker studies of rheumatoid arthritis (RA), Sjögren's disease, and other systemic diseases [13-15]. Analysis of tears may also be a non-invasive approach to assess biomarkers of uveitis, in order to identify children with JIA who are most susceptible to uveitis, and it may be reflective of intraocular pathology. Differences in the levels of cytokines and chemokines have been reported in the tears of adults with uveitis compared to healthy subjects [16].

Our objectives were to use tears to (1) determine if cytokines and chemokines reported to be present in $\mathrm{AqH}$ of children with uveitis are observed in tears and (2) assess the comparative tear proteomic milieu in children with JIA-U and I-CAU.

\section{Results}

\section{Characteristics of children}

Nine affected eyes of seven children (two oligoarticular and one polyarticular RF negative JIA-U and 4 I-CAU) were evaluated (Table 1). LC-MS/MS/SPS-MS3 was used to determine proteomic profiles from tears collected using Schirmer strips. We quantified 1804 unique proteins, following a QC step that filtered proteins based on expression levels, and 1605 proteins had a present call in half of the samples. These 1605 proteins were used in subsequent analysis.

Table 1 Demographics and clinical characteristics of children

\begin{tabular}{llll}
\hline$N$ (\%) unless otherwise specified & All & JIA-U & I-CAU \\
& $N=7$ & $N=3$ & $N=4$ \\
& 9 eyes & 4 eyes & 5 eyes \\
\hline Female & $6(86)$ & $3(100)$ & $3(75)$ \\
Race & & & \\
Caucasian & $3(43)$ & $2(67)$ & $1(25)$ \\
African-American & $4(57)$ & $1(33)$ & $3(75)$ \\
Non-Hispanic & $7(100)$ & $3(100)$ & $4(100)$ \\
Disease characteristics & & & \\
Median age at uveitis diagnosis, years, SD & 6,9 & $6,5.6$ & $8.8,5.3$ \\
Median age at tear collection, years, SD & $15,1.8$ & - & - \\
Bilateral disease & $6(86)$ & $2(67)$ & $4(100)$ \\
Ocular complications & & & \\
ANA-positive & $7(100)$ & $3(100)$ & $4(100)$ \\
Medications & $4(57)$ & $3(100)$ & $1(25)$ \\
Topical glucocorticoids & & & \\
Topical glaucoma medications & $4(57)$ & $1(33)$ & $3(75)$ \\
Methotrexate & $1(14)$ & $0(0)$ & $1(25)$ \\
Mycophenolate mofetil & $4(57)$ & $1(33)$ & $3(75)$ \\
Infliximab & $1(14)$ & $0(0)$ & $1(25)$ \\
Adalimumab & $1(14)$ & $1(33)$ & $0(0)$ \\
\hline & $2(28)$ & $1(33)$ & $1(25)$ \\
\hline
\end{tabular}

a Ocular complications: synechiae, cataracts, glaucoma, ocular hypertension, band keratopathy, cystoid and macular edema

\section{Cytokines/chemokines in tears}

We first performed a targeted analysis for cytokines and chemokines reported in AqH (Additional file 1) [8-11]. We detected CD14, S100 calcium binding protein (S100) A8/A9, serum amyloid A (SAA1), latency-associated peptide (LAP3), TTR, and macrophage migration inhibitory factor (MIF) in all nine tear samples. On further comparison, CD14, S100A8, and SAA1 had higher expression in children with JIA-U compared to I-CAU, while S100A9, LAP3, TTR, and MIF had lower expression in children with JIA-U (Fig. 1).

\section{Tear proteins in children differentially detected between JIA-U and I-CAU}

We identified 29 unique proteins with significant differences between JIA-U and I-CAU. We then performed hierarchical clustering analysis using these differentially expressed proteins (Fig. 2). Green, black, and red reflect high, average, and low expression, respectively, in JIA-U compared to I-CAU. As shown in Fig. 2, these proteins could differentiate between samples obtained from children with JIA-U and I-CAU. Fourteen proteins were expressed at a higher level in JIA-U, and 15 were expressed at a lower level in JIA-U compared to I-CAU. Proteins with biological relevance were SAA1, metalloproteinase inhibitor 1 (TIMP1), beta-hexosaminidase subunit beta (HEXB), and serine/threonine-protein kinase/endoribonuclease IRE1 (ERN1), which were increased in JIA-U. Dnaj homolog subfamily B member 1 (DNAJB1) was decreased in JIA-U compared to I-CAU. The relevance of the other proteins is unknown (Fig. 2). These observations suggest that tear biomarker profiles could be useful in distinguishing subtypes of anterior uveitis.

\section{Network analyses}

Gene ontology annotation using DAVID categorized pathways of molecular functions, cellular components, and biological processes. Ontology revealed 15 out of 29 altered proteins in pathways related to extracellular exosomes $\left(p=6.4 \times 10^{-6}\right)$ in both groups.

\section{Discussion}

We demonstrated that tears, an easily obtained biospecimen, can detect biomarkers previously found to be present in $\mathrm{AqH}$ in children with uveitis. Furthermore, we found potentially novel cytokines, chemokines, and proteins in tears differentially expressed in JIA-U compared to I-CAU, suggesting intrinsic biologic differences, despite similar clinical phenotypes. While these findings require replication, they suggest that tears have a similar profile to $\mathrm{AqH}$ and may be useful in biomarker studies, and that there may be pathophysiologic differences between JIA-U and I-CAU. 


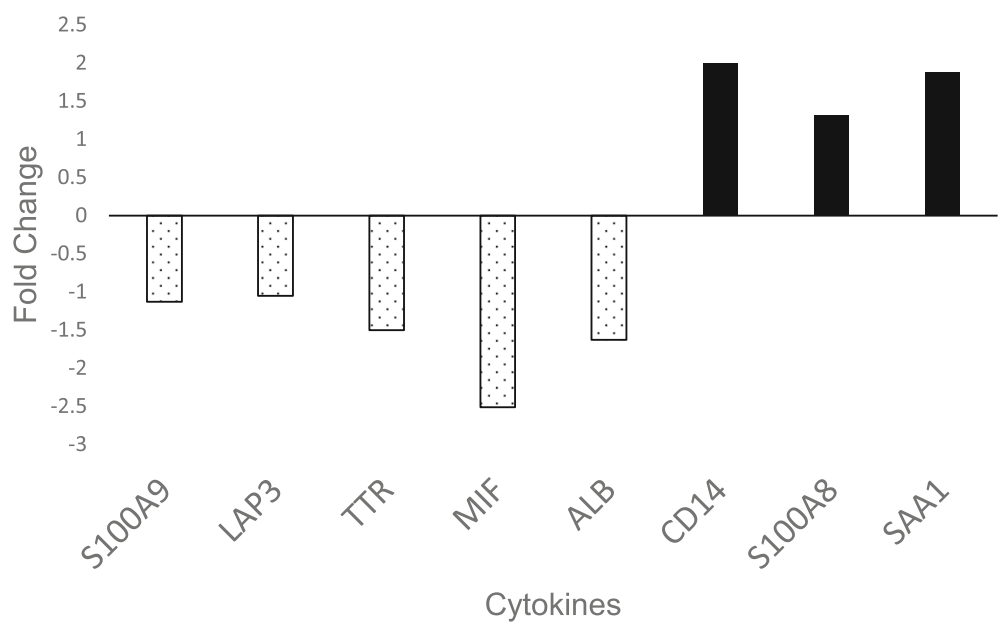

Fig. 1 Differences in expression level (fold change) of seven cytokines of interest from earlier aqueous humor and serum studies [8-12] in patients with JIA-U compared to those with I-CAU. Black bars depict proteins that are upregulated, and stippled bars show proteins that are downregulated
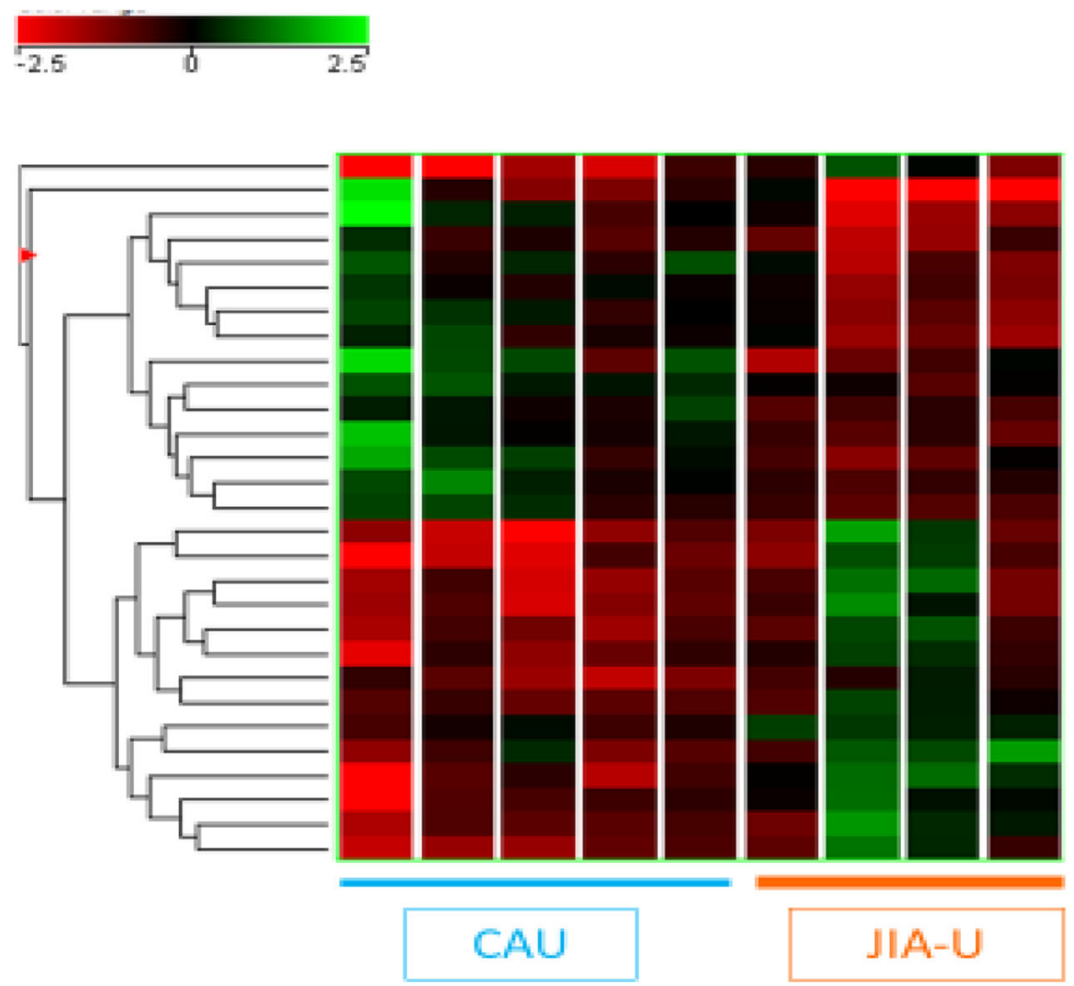

SMOC1

TSTDi1

EIF 4 H

THSAP

DHAJB1

EFUCHS

EPS1SL1

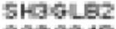

$\operatorname{cosct} 40$

CTMFA.1

Preba

APIt

UMNB2

HW. WhPAF

CHUP1B

TiMP

EFA1

20ㄴㄷㅇㅛ

PERF

HEXE

FUCA-1

SAan1

RARAES-1

HEB

DHET1

AUTrea

CtAL

SEMHOG

SIL1

\section{CAU}

\section{ل」IA-U}

Fig. 2 Cluster analysis of 29 proteins differentially expressed between patients with JIA-U (orange) and I-CAU (blue). The list of differentially expressed proteins was generated using Mann-Whitney $U$ test, with $p<0.05$. Complete linkage clustering algorithm, in which distance is a measure of similarity, was used to generate the hierarchical clustering tree. In the tree, each row represents a separate protein and each column represents a sample. The normalized expression level of each protein (rows) in each sample (columns) is indicated by color. Green, black, and red reflect high, medium, and low expression, respectively 
$\mathrm{AqH}$ is secreted by the ciliary body and circulates in the anterior chamber of the eye, where inflammatory cells appear. Studies of AqH in adults and children with uveitis have shown correlations between certain cytokines (IL-6, IL-8 IL-10, IFN- $\gamma$, sVCAM, RANTES, and IP-10) and uveitis activity and between others (IL-1 $\beta$, IL-2, IL-6, IL-8, IL-10, tumor necrosis factor- $\alpha$, and vascular endothelial growth factor) and systemic immunosuppressive treatment $[10,17-19]$. AqH therefore appears to reflect underlying uveitis activity; however, $\mathrm{AqH}$ collection is invasive and thus not feasible in children with JIA alone or when ocular surgery is not otherwise indicated. Tears are already utilized for biomarker discovery in systemic diseases with and without ocular involvement, such as Sjögren syndrome, RA, thyroid ophthalmopathy, malignancy, multiple sclerosis, and diabetes mellitus [13-15, 20-24]. If tears can reflect uveitis activity, similar to $\mathrm{AqH}$, it may be a promising biospecimen for uveitis biomarker studies. Carreon and colleagues report differences in the cytokine and chemokine tear profiles of adult uveitis patients compared to healthy controls and differences based on uveitis anatomic classification, wherein patients with anterior and panuveitis had increased concen- trations compared to controls and intermediate and posterior uveitis [25].

We confirmed the presence of sCD14, S100A8/A9, SAA1, LAP3, and TTR in tears, which have been identified in $\mathrm{AqH}$ and serum of children with JIA-U (Table 2) $[8-10,12,26]$. There were differences in the level of expression based on underlying uveitis diagnosis, but the relevance of their presence needs further exploration, as these cytokines are non-specific and are present in the serum of individuals with various autoimmune diseases.
Nevertheless, this preliminary work supports the premise that tears may also be used in biomarker studies in children at risk for developing de novo eye disease.

One prior study examined tears for biomarkers in 13 patients with JIA-U and 3 controls using high-resolution MS and report 236 proteins as candidate biomarkers for JIA-U [27]. While these specific findings were not replicated in our study, our comparison groups differed (i.e., normal controls were not used as a comparison group in our study).

We noted 29 unique proteins in the tear profiles of children with JIA-U and I-CAU. SAA1, HEXB, TIMP1, and ERN1 had increased expression in JIA-U and have been reported in patients with RA and JIA. They play a role in activation of fibroblast-like synoviocytes (FLS), immune modulation, angiogenesis, apoptosis, and invasive cell migration, where they are important in inflammatory response and tissue injury or as markers of disease activity [28-34]. SAA1 is a major acute phase protein expressed in response to inflammation and tissue injury in patients with RA [28-30]. HEXB with co- factor GM2 activator protein catalyze the degradation of the ganglioside GM2 and other molecules containing terminal $\mathrm{N}$-acetyl hexosamines in patients with RA [31]. TIMPs were increased in the plasma of untreated children with JIA, have been associated with levels of matrix metalloproteinase (MMP)-1, MMP-3, and TIMP1 in paired serum and synovial fluid also in those with JIA, and were found in $\mathrm{AqH}$ of patients with glaucoma [32, 33, 35]. DNAJB1 had low expression in children with JIA-U compared to those with I-CAU and has been associated with JIA [36]. In our study, proteins associated with arthritis were increased in the tear profile of

Table 2 Cytokines detected in tears of JIA-U and I-CAU in this study and from aqueous humor in previous studies

\begin{tabular}{|c|c|c|c|c|c|}
\hline Authors, year & Disease $^{a}(n)$ & Samples & $\begin{array}{l}\text { Cytokines/ } \\
\text { chemokines }\end{array}$ & Direction & $\begin{array}{l}\text { Present findings JIA-U vs. I- } \\
\text { CAU }\end{array}$ \\
\hline \multirow[t]{4}{*}{$\begin{array}{l}\text { Haasnoot, } 2016 \\
{[9]}\end{array}$} & $\begin{array}{l}J A-U[21] \\
\text { CAU [15] } \\
\text { IU [28] } \\
\text { Controls [8] }\end{array}$ & $\mathrm{AqH}$ & $\mathrm{IL}-29 / \mathrm{IFN}-\lambda 1$ & Decreased in JIA-U vs CAU, IU and controls & Not detected \\
\hline & & & LAP & Increased in JIA-U vs IU and controls & Decreased \\
\hline & & & S100A8 & Decreased JIA-U vs. IU & Increased \\
\hline & & & sCD14 & Increased JIA-U vs. controls & Increased \\
\hline \multirow[t]{2}{*}{$\begin{array}{l}\text { Walscheid, } 2015 \\
{[12]}\end{array}$} & $\begin{array}{l}J A-U[17] \\
\text { IAU [12] } \\
\text { Controls [16] }\end{array}$ & $\mathrm{AqH}$ & S100A8 & Increased JIA-U and IAU vs. controls & Increased \\
\hline & & & S100A9 & Increased JIA-U and IAU vs. controls & Decreased \\
\hline Ayuso, $2013[8]$ & $\begin{array}{l}\text { JIA-U [14] } \\
\text { CAU [8] } \\
\text { Other Uveitis } \\
\text { [30] } \\
\text { Controls [20] }\end{array}$ & $\mathrm{AqH}$ & TTR & $\begin{array}{l}\text { Increased JIA-U and CAU vs. other uveitis and } \\
\text { controls }\end{array}$ & Increased \\
\hline
\end{tabular}

JIA-U JIA-associated uveitis, CAU chronic anterior uveitis, IU idiopathic uveitis which included non-anterior uveitis, IAU idiopathic anterior uveitis, IL-29/IFN- $\lambda$ I interleukin-29/interferon- $\lambda 1$, LAP latency associated peptide, S100 S100 calcium binding protein, $s C D 14$ soluble cluster of differentiation 14 , $T T R$ transthyretin ${ }^{a}$ Disease categories are listed are as they were presented in each study and do not necessarily conform to our disease descriptions 
children with JIA-U. There were other proteins of uncertain biological relevance that differed between the groups. Further study is needed in larger cohorts to determine their importance in uveitis. Our findings also show value in children with JIA, as we were able to detect arthritis-related markers.

Pathway analyses revealed that detected proteins were involved in extracellular exosomes. This pathway is related to proteins released from vesicles into the extracellular region by fusion of the limiting endosomal membrane of a multivesicular body with the plasma membrane. Because tears are typically acellular, these findings suggest that proteins may be secreted from cells possibly having differential gene expression related to underlying uveitis activity. Further study into the role of extracellular exosomes in the pathogenesis of uveitis and the cells secreting these proteins in children with uveitis should be investigated.

\section{Strengths and limitations}

This uncontrolled pilot study included only a small number of children as a proof-of-principle that tears can identify proteins found in $\mathrm{AqH}$. A limitation is that the sample size was too small to adjust for the potential confounders of treatment effect and level of disease activity, so these results should be considered as hypothesis-generating (Table 3). Differences in protein, cytokine, and chemokine levels have been reported in studies that examined $\mathrm{AqH}$ of children with uveitis and tears of adults with uveitis compared to controls without uveitis. However, it is important to examine the tear profile of children with JIA without uveitis and pediatric healthy controls without ocular disease since the controls in $\mathrm{AqH}$ studies had congenital cataracts and glaucoma. Serial tear collection with longitudinal follow-up is ongoing in children with JIA, other forms of uveitis, and pediatric controls to replicate and extend these findings to a larger group of study participants. These future studies will allow further comparisons by disease group, uveitis activity, and treatment response. A small number of children were included in our study, and it is not a reflection of the number of children diagnosed with uveitis in our practice. This was a pilot study to determine if we could detect proteins in tears that were previously detected in $\mathrm{AqH}$ and to refine our processes and methods. Not all children contributed tears from both eyes, as only the eyes with uveitis were included. We were not able to include all samples in our analysis due to issues with protein recovery which may be related to sample collection. Also, analyses did not adjust for correlation between the eyes of patients with bilateral disease. A strength of this study is that it is a pediatric study using state-of-the art techniques and demonstrates the feasibility of tear sample collection in this population.

\section{Conclusions}

We demonstrated the utility of tears for biomarker studies in children with JIA and uveitis. The preliminary

Table 3 Characteristics of children with chronic anterior uveitis

\begin{tabular}{|c|c|c|c|c|c|c|c|}
\hline Patient & & Diagnosis, laterality & $\begin{array}{l}\text { Age at } \\
\text { diagnosis, } \\
\text { years }\end{array}$ & $\begin{array}{l}\text { Uveitis } \\
\text { Active }\end{array}$ & $\begin{array}{l}\text { Number } \\
\text { of eyes } \\
\text { included }\end{array}$ & $\begin{array}{l}\text { Topical meds at time of } \\
\text { collection }\end{array}$ & $\begin{array}{l}\text { Systemic meds at time of } \\
\text { collection }\end{array}$ \\
\hline 1 & $\begin{array}{l}\text { 19-year-old } \\
\mathrm{NH} \mathrm{AA} \\
\text { female }\end{array}$ & $\begin{array}{l}\text { Oligoarticular JIA-associated } \\
\text { uveitis, unilateral }\end{array}$ & 12 & $\begin{array}{l}\text { No AC cells } \\
\text { rare OD; } \\
\text { None OS }\end{array}$ & 1 & $\begin{array}{l}\text { Prednisolone acetate every } \\
\text { hour OD }\end{array}$ & Methotrexate oral \\
\hline 2 & $\begin{array}{l}\text { 15-year-old } \\
\mathrm{NH} \text { white } \\
\text { female }\end{array}$ & $\begin{array}{l}\text { Oligoarticular JIA-associated } \\
\text { uveitis, bilateral }\end{array}$ & 1 & $\begin{array}{l}\text { No AC cells } \\
0 \text { OU }\end{array}$ & 2 & None & Adalimumab injections \\
\hline 3 & $\begin{array}{l}17 \text {-year-old } \\
\text { NHW } \\
\text { female }\end{array}$ & $\begin{array}{l}\text { Polyarticular rheumatoid } \\
\text { factor negative JIA- } \\
\text { associated uveitis, bilateral }\end{array}$ & 5 & $\begin{array}{l}\text { No AC cells } \\
0 \text { OU }\end{array}$ & 1 & None & Infliximab infusions \\
\hline 4 & $\begin{array}{l}15 \text {-year-old } \\
\text { NHW } \\
\text { female }\end{array}$ & Idiopathic CAU, bilateral & 3 & $\begin{array}{l}\text { No AC cells } \\
\text { O OU }\end{array}$ & 1 & None & Mycophenolate oral \\
\hline 5 & $\begin{array}{l}\text { 17-year-old } \\
\mathrm{NH} \mathrm{AA} \\
\text { female }\end{array}$ & Idiopathic CAU, bilateral & 15 & $\begin{array}{l}\text { Yes } A C \text { cells } \\
1+O U\end{array}$ & 2 & $\begin{array}{l}\text { Difluprednate } 1 \text { drop daily } \\
\text { OU }\end{array}$ & Methotrexate injections \\
\hline 6 & $\begin{array}{l}\text { 14-year-old } \\
\mathrm{NH} \mathrm{AA} \\
\text { female }\end{array}$ & Idiopathic CAU, bilateral & 11 & $\begin{array}{l}\text { Yes } A C \text { cells } \\
1+O U\end{array}$ & 1 & $\begin{array}{l}\text { Difluprednate } 1 \text { drop daily } \\
\text { OU }\end{array}$ & Methotrexate injections \\
\hline 7 & $\begin{array}{l}\text { 12-year-old } \\
\mathrm{NH} \mathrm{AA} \\
\text { male }\end{array}$ & Idiopathic CAU, bilateral & 6 & $\begin{array}{l}\text { No AC cells } \\
0 \text { OU }\end{array}$ & 1 & $\begin{array}{l}\text { Prednisolone acetate } 1 \text { drop } \\
2 \text { times per day OS and } \\
\text { Timolol maleate }\end{array}$ & $\begin{array}{l}\text { Prednisolone acetate } 1 \\
\text { drop } 2 \text { times per day OS } \\
\text { and Timolol maleate }\end{array}$ \\
\hline
\end{tabular}

JIA-U JIA-associated uveitis, $C A U$ chronic anterior uveitis, $N H$ non-Hispanic, $A A$ African-American, $W$ White, $A C$ anterior chamber, $O D$ right eye, $O S$ left eye, $O U$ bilateral eyes 
evidence of proteomic differences between JIA-U and I-CAU related to inflammatory arthritis generate hypotheses that warrant further investigation. Tear collection is well tolerated in children and has likely application in JIA studies. The use of tears in biomarker studies may improve our understanding of the underlying mechanisms involved in ocular inflammation which could lead to discovery of biomarkers for the early detection of uveitis and better prediction models for susceptibility in children with JIA, monitoring of disease, and treatment response.

\section{Methods}

We performed a cross-sectional study approved by the Emory University Institutional Review Board, which con- formed to the US Health Insurance Portability and Privacy Act requirements. Informed consent/assent was obtained from parents and children accordingly. We followed the tenets of the Declaration of Helsinki.

\section{Subjects}

Children with JIA-U and I-CAU were screened and enrolled at the Emory Eye Center during their routine ophthalmology clinic visits from October 2015 to March 2017. Inclusion criteria were (1) a diagnosis of chronic anterior uveitis diagnosed by a uveitis fellowship-trained ophthalmologist, with or without JIA by the International League of Associations for Rheumatology classification in children with arthritis [37] and (2) 5 years of age or older.

\section{Data collection}

Data collected by medical record review included date of birth, sex, self-reported race/ethnicity, JIA category, uveitis characteristics (onset date, diagnosis date, laterality, ocular complications), anterior chamber (AC) cell score per standardization of uveitis nomenclature (SUN) criteria [38], and ANA status. Use of topical and systemic medications was reviewed at time of tear collection. Data from the ophthalmic exam were recorded at time closest to tear collection.

\section{Tear collection}

Ophthalmologists or trained study staff collected tear samples from children using Schirmer strips which are routinely used for dry eye evaluation. We included eyes with a history of uveitis only. After local anesthesia (topical $0.5 \%$ proparacaine hydrochloride, Bausch \& Lomb, Roches- ter, NY, USA) was administered, residual anesthetic fluid was removed from the conjunctival cul-de-sac while avoiding corneal contact. A Schirmer strip was placed into the temporal inferior fornix of each eye (approximately $6 \mathrm{~mm}$ from the lateral canthus), avoiding the corneal surface. Reflex tearing was avoided as much as possible. The eye was closed for $5 \mathrm{~min}$. Alternatively, the strip was removed when fully saturated (maximum $5 \mathrm{~min}$ ). The Schirmer strip was placed in an Eppendorf micro centrifuge tube on ice and stored at $80{ }^{\circ} \mathrm{C}$ until processing.

\section{Schirmer strip protein extraction}

Each strip was soaked and vortexed in $500 \mathrm{uL}$ of urea lysis buffer (8 M urea, $100 \mathrm{mM} \mathrm{NaH2PO4,} \mathrm{pH} \mathrm{8.5),} \mathrm{in-}$ cluding $5 \mathrm{uL}(100 \times$ stock) HALT protease and phosphatase inhibitor cocktail (Pierce). Protein supernatants were transferred to $1.5-\mathrm{mL}$ Eppendorf tubes, and proteins were extracted as previously published [39]. An aliquot equivalent to $10 \mu \mathrm{g}$ of total protein was removed from each sample and combined to obtain two global internal standards (GIS) used later for tandem mass tag (TMT) labeling (total was split into two aliquots of $40 \mu \mathrm{g}$ of total protein). For each sample, $40 \mu \mathrm{g}$ of total protein was processed.

\section{TMT labeling}

The samples were randomized over four TMT 10-plex batches. In each batch, the GIS samples took up channels 1 and 10 (TMT-126 and TMT-131, respectively). Labeling was performed according to the manufacturer's protocol, and cleanup was performed according to a previously published method [39].

\section{ERLIC fractionation}

The protocol for electrostatic repulsion interaction chromatography (ERLIC) fractionation was adapted from a published method [40].

\section{LC-MS/MS analysis with MS3 quantitation}

Liquid chromatography-tandem mass spectrometry with MS3 selective precursor selection (LC-MS/MS/ SPS-MS3) was used to identify proteins in patients with JIA-U $(n=3)$ and I-CAU $(n=4)$. LC-MS/MS/SPS-MS3 was adapted from a published procedure $[39,41]$.

\section{Database search and TMT quantitation}

MS/MS spectra were searched against a Uniprot curated human database (downloaded on 4/15/2015 with 90,300 sequences) with Proteome Discoverer 2.1 (ThermoFisher Scientific, San Jose, CA, USA). Search parameters and protein quantitation using MS3 reporter ions were previously reported [39]. Ratio of sample over the GIS of normalized channel abundances were used for comparison across all samples.

\section{Statistical analysis}

Descriptive statistics were performed using frequencies, percentages, medians, and IQR, as appropriate. 
Protein expression values were analyzed using algorithms available in GeneSpring GX 13.0 (Agilent Technologies Inc., Santa Clara, CA, USA). Differential expression values were identified using Mann-Whitney $U$ tests and presented as a heatmap. Hierarchical clustering using complete linkage was used to group proteins and samples by expression patterns.

Network analysis explored associations among proteins involved in different biological processes to find the most significant shared pathways using DAVID 6.7 (the Database for Annotation, Visualization and Integration Discovery) [42, 43]. The input data for the network analyses consisted of the significantly expressed proteins represented on the heatmap analysis.

Statistical significance was defined as two-sided $p<$ 0.05. Each tear sample was treated independently. All analyses were conducted using SAS v. 9.4 for Windows (Cary, NC, USA).

\section{Additional file}

Additional file 1: Cytokines and chemokines reported in pediatric uveitis biomarker studies using aqueous humor. (DOCX 13 kb)

\section{Abbreviations \\ AC: Anterior chamber; ANA: Antinuclear antibody; AqH: Aqueous humor; CAU: Chronic anterior uveitis; DAVID: The Database for Annotation, Visualization and Integration Discovery; DNAJB1: Dnaj homolog subfamily B member 1; ERLIC: Electrostatic repulsion interaction chromatography; ERN1: Serine/threonine-protein kinase/endoribonuclease IRE1; FLS: Fibroblast- like synoviocytes; GIS: Global internal standards; HEXB: Beta-hexosaminidase subunit beta; I-CAU: Idiopathic chronic anterior uveitis; IL-29/IFN- $\lambda 1$ : Interleukin-29/interferon- $\lambda 1$; JIA-U: JIA-associated euveitis; JIA: Juvenile idiopathic arthritis; LAP3: Latency-associated peptide; LC-MS/MS: Liquid chromatography-tandem mass spectrometry; LC-MS/MS/SPS-MS3: Liquid chromatography-tandem mass spectrometry with synchronous precursor- based selection; MIF: Macrophage migration inhibitory factor; MMP: Matrix metalloproteinase; RA: Rheumatoid arthritis; RF: Rheumatoid factor; S100: S100 calcium-binding protein; SAA1: Serum amyloid A; SUN: Standardization of uveitis nomenclature; TIMP1: Metalloproteinase inhibitor 1; TMT: Tandem mass tag; TTR: Transthyretin}

\section{Acknowledgements}

The authors thank Theresa Hennard and Najima Mwase for their administrative assistance.

\section{Funding}

Dr. Angeles-Han was supported by Award Number K23EY021760 from the National Eye Institute, the Rheumatology Research Foundation, and the Cincinnati Children's Hospital Medical Center Research Innovation and Pilot fund. These grants supported the design of the study and collection, analysis, interpretation of the data, and in writing the manuscript.

Dr. Prahalad is supported, in part, by a grant from the Marcus Foundation Inc., Atlanta. Dr. Holland is supported by the Maggi Kelly Vision Fund (UCLA Stein Eye Institute) and the Fund for Children with Uveitis (UCLA Stein Eye Institute).

\section{Availability of data and materials}

As in manuscript.

\section{Authors' contributions}

All authors were involved in drafting the article or revising it critically for important intellectual content, and all authors approved the final version to be submitted for publication. STA-H is accountable for all aspects of the work in ensuring that questions related to the accuracy or integrity of any part of the work are appropriately investigated and resolved. STA-H, SP, and GNH contributed to the study conception and design. STA-H, KJ, PP, KAR-S, and SY did the acquisition of the data. STA-H, MA, DD, NF, GNH, and ST took part in the analysis and interpretation of the data.

\section{Ethics approval and consent to participate}

This study was approved by the Emory University Institutional Review Board, which conformed to the US Health Insurance Portability and Privacy Act requirements. Informed consent/assent was obtained from the parents and children accordingly. We followed the tenets of the Declaration of Helsinki.

\section{Consent for publication}

Not applicable.

\section{Competing interests}

Dr. Steven Yeh is a consultant for Santen and Clearside Biomedical not related to this study. Dr. Prahalad has served on an advisory committee for Novartis Pharmaceuticals not related to this study. The other authors declare that they have no competing interests.

\section{Publisher's Note}

Springer Nature remains neutral with regard to jurisdictional claims in published maps and institutional affiliations.

\section{Author details}

${ }^{1}$ Division of Rheumatology, Cincinnati Children's Hospital Medical Center, 3333 Burnet Avenue, MLC 4010, Cincinnati, OH 45229, USA. ²Department of Pediatrics, University of Cincinnati, Cincinnati, OH, USA. ${ }^{3}$ Department of Ophthalmology, Emory Eye Center, Emory University School of Medicine, 1365 Clifton Rd B, Atlanta, GA 30322, USA. ${ }^{4}$ Emory Integrated Proteomics Core, Emory University, 1510 Clifton Rd, Atlanta, GA 30322, USA. ${ }^{5}$ Childrens Healthcare of Atlanta, Emory Children's Center, 2015 Uppergate Drive, Atlanta, GA 30322, USA. ${ }^{6}$ Department of Pediatrics, Emory University School of Medicine, Atlanta, GA, USA. 'Department of Human Genetics, Emory University School of Medicine, Atlanta, GA, USA. ${ }^{8}$ Division of Biostatistics and Epidemiology, Cincinnati Children's Hospital Medical Center, University of Cincinnati, 3333 Burnet Avenue, MLC 5041, Cincinnati, OH 45229, USA. ' UCLA Stein Eye Institute and David Geffen School of Medicine at University of California, 100 Stein Plaza, Los Angeles, CA 90095-7000, USA.

Received: 21 April 2018 Accepted: 6 September 2018

Published online: 16 October 2018

\section{References}

1. Ravelli A, Martini A (2007) Juvenile idiopathic arthritis. Lancet 369:767-778

2. Holland GN, Denove CS, Yu F (2009) Chronic anterior uveitis in children: clinical characteristics and complications. Am J Ophthalmol 147(667-678):e5

3. Angeles-Han ST, Pelajo CF, Vogler LB, Rouster-Stevens K, Kennedy C, Ponder L et al (2013) Risk markers of juvenile idiopathic arthritis-associated uveitis in the Childhood Arthritis and Rheumatology Research Alliance (CARRA) registry. J Rheumatol 40:2088-2096

4. Angeles-Han ST, McCracken C, Yeh S, Jenkins K, Stryker D, Rouster-Stevens K et al (2015) Characteristics of a cohort of children with juvenile idiopathic arthritis and JIA-associated uveitis. Pediatr Rheumatol Online J 13:1-10

5. Cassidy J, Kivlin J, Lindsley C, Nocton J (2006) Section on rheumatology, section on ophthalmology. Ophthalmologic examinations in children with juvenile rheumatoid arthritis. Pediatrics 117:1843-1845

6. Reininga JK, Los LI, Wulffraat NM, Armbrust W (2008) The evaluation of uveitis in juvenile idiopathic arthritis (JIA) patients: are current ophthalmologic screening guidelines adequate? Clin Exp Rheumatol 26:367-372

7. Heiligenhaus A, Niewerth M, Ganser G, Heinz C, Minden K (2007) Prevalence and complications of uveitis in juvenile idiopathic arthritis in a populationbased nation-wide study in Germany: suggested modification of the current screening guidelines. Rheumatol 46:1015-1019

8. Kalinina Ayuso V, de Boer JH, Byers HL, Coulton GR, Dekkers J, de Visser L et al (2013) Intraocular biomarker identification in uveitis associated with juvenile idiopathic arthritis. Invest Ophthalmol Vis Sci 54:3709-3720

9. Haasnoot AJ, Kuiper JJ, Hiddingh S, Schellekens PA, de Jager W, Imhof SM et al (2016) Ocular fluid analysis in children reveals interleukin-29/interferon- 
lambda1 as a biomarker for juvenile idiopathic arthritis associated uveitis. Arthritis Rheumatol 68:1769-1779

10. Sijssens KM, Rijkers GT, Rothova A, Stilma JS, Schellekens PAWJF, de Boer JH (2007) Cytokines, chemokines and soluble adhesion molecules in aqueous humor of children with uveitis. Exp Eye Res 85:443-449

11. Sijssens KM, Rijkers GT, Rothova A, Stilma JS, de Boer JH (2008) Distinct cytokine patterns in the aqueous humor of children, adolescents and adults with uveitis. Ocul Immunol Inflamm 16:211-216

12. Walscheid K, Heiligenhaus A, Holzinger D, Roth J, Heinz C, Tappeiner C et al (2015) Elevated S100A8/A9 and S100A12 serum levels reflect intraocular inflammation in juvenile idiopathic arthritis-associated uveitis: results from a pilot study. Invest Ophthalmol Vis Sci 56:7653-7660

13. Aluru SV, Shweta A, Bhaskar S, Geetha K, Sivakumar RM, Utpal T et al (2016) Tear fluid protein changes in dry eye syndrome associated with rheumatoid arthritis: a proteomic approach. Ocul Surf 15:112-129

14. Aass C, Norheim I, Eriksen EF, Børnick EC, Thorsby PM, Pepaj M (2016) Comparative proteomic analysis of tear fluid in Graves' disease with and without orbitopathy. Clin Endocrinol 85:805-812

15. Agrawi LA, Galtung HK, Vestad B, Øvstebø R, Thiede B, Rusthen $S$ et al (2017) Identification of potential saliva and tear biomarkers in primary Sjögren's syndrome, utilising the extraction of extracellular vesicles and proteomics analysis. Arthritis Res Ther 19:14

16. Carreño E, Portero A, Herreras JM, García-Vázquez C, Whitcup SM, Stern ME et al (2016) Cytokine and chemokine tear levels in patients with uveitis. Acta Ophthalmol 95(5):e405-e414

17. Abu El-asrar AM, Struyf S, Descamps FJ, Al-Obeidan SA, Proost P, Van Damme J et al (2004) Chemokines and gelatinases in the aqueous humor of patients with active uveitis. Am J Ophthalmol 138:401-411

18. van Kooij B, Rothova A, Rijkers GT, JDF d G-M (2006) Distinct cytokine and chemokine profiles in the aqueous of patients with uveitis and cystoid macular edema. Am J Ophthalmol 142:192-194

19. Hernández Garfella ML, Palomares Fort P, Román Ivorra JA, Cervera Taulet E (2015) Aqueous humor levels of different interleukins $1-\beta, 2,6$ and 10, tumor necrosis factor- $a$ and vascular endothelial growth factor in uveitis treated with adalimumab. J Ophthalmic Vis Res 10:49-54

20. Salvisberg C, Tajouri N, Hainard A, Burkhard PR, Lalive PH, Turck N (2014) Exploring the human tear fluid: discovery of new biomarkers in multiple sclerosis. Proteomics Clin Appl 8:185-194

21. Böhm D, Keller K, Pieter J, Boehm N, Wolters D, Siggelkow W et al (2012) Comparison of tear protein levels in breast cancer patients and healthy controls using a de novo proteomic approach. Oncol Rep 28:429-438

22. Torok Z, Peto T, Csosz E, Tukacs E, Molnar AM, Berta A et al (2015) Combined methods for diabetic retinopathy screening, using retina photographs and tear fluid proteomics biomarkers. J Diabetes Res 2015:1-8

23. Türkçüoğlu P, Arat YO, Kan E, Kan EK, Chaudhry IA, Koca S et al (2015) Association of disease activity with serum and tear IL-2 levels in Behçet disease. In: Ocul Immunol Inflamm 24:1-6 A

24. Simonini G, Paudyal P, Jones GT, Cimaz R, Macfarlane GJ (2013) Current evidence of methotrexate efficacy in childhood chronic uveitis: a systematic review and meta-analysis approach. In: Rheumatol 52:825-831 A

25. Carreño E, Portero A, Herreras JM, García-Vázquez C, Whitcup SM, Stern ME et al (2017) Cytokine and chemokine tear levels in patients with uveitis. Acta Ophthalmol 95:e405-e414

26. Haasnoot AJ, van Tent-Hoeve M, Wulffraat NM, Schalij-Delfos NE, Los LI, Armbrust W et al (2015) Erythrocyte sedimentation rate as baseline predictor for the development of uveitis in children with juvenile idiopathic arthritis. Am J Ophthalmol 159:372-377 e1

27. Chasnyk V, Nekhai S, Hynes A, Ammosova T, Obukhov Y, Gaidar E et al (2013) Proteomic profile of tears: can it help to diagnose juvenile arthritis associated uveitis prior to the clinical signs of joints inflammation (abstract). Arthritis Rheum 65:1891

28. Connolly M, Marrelli A, Blades M, McCormick J, Maderna P, Godson C et al (2010) Acute serum amyloid a induces migration, angiogenesis, and inflammation in synovial cells in vitro and in a human rheumatoid arthritis/ SCID mouse chimera model. J Immunol 184:6427-6437

29. Connolly M, Mullan RH, Mccormick J, Matthews C, Sullivan O, Kennedy A et al (2012) Acute-phase serum amyloid A regulates tumor necrosis factor a and matrix turnover and predicts disease progression in patients with inflammatory arthritis before and after biologic therapy. Arthritis Rheum 64:1035-1045

30. Hwang YG, Balasubramani GK, Metes ID, Levesque MC, Bridges SL, Moreland LW (2016) Differential response of serum amyloid A to different therapies in early rheumatoid arthritis and its potential value as a disease activity biomarker. Arthritis Res Ther 18:108

31. Pászzói M, Nagy G, Géher P, Lakatos T, Tóth K, Wellinger K et al (2009) Gene expression and activity of cartilage degrading glycosidases in human rheumatoid arthritis and osteoarthritis synovial fibroblasts. Arthritis Res Ther 11:R68

32. Winsz-Szczotka K, Komosińska-Vassev K, Kuźnik-Trocha K, Gruenpeter A, Lachór-Motyka I, Olczyk K (2014) Influence of proteolytic-antiproteolytic enzymes and prooxidative-antioxidative factors on proteoglycan alterations in children with juvenile idiopathic arthritis. Clin Biochem 47:829-834

33. Peake NJ, Khawaja K, Myers A, Jones D, Cawston TE, Rowan AD et al (2005) Levels of matrix metalloproteinase (MMP)-1 in paired sera and synovial fluids of juvenile idiopathic arthritis patients: relationship to inflammatory activity, MMP-3 and tissue inhibitor of metalloproteinases-1 in a longitudinal study. Rheumatology (Oxford) 44:1383-1389

34. Qiu Q, Zheng Z, Chang L, Zhao Y-S, Tan C, Dandekar A et al (2013) Toll-like receptor-mediated IRE 1 a activation as a therapeutic target for inflammatory arthritis. EMBO J 32:2477-2490

35. Ashworth Briggs EL, Toh T, Eri R, Hewitt AW, Cook AL (2015) TIMP1, TIMP2, and TIMP4 are increased in aqueous humor from primary open angle glaucoma patients. Mol Vis 21:1162-1172

36. Massa M, Passalia M, Manzoni SM, Campanelli R, Ciardelli L, Yung GP et al (2007) Differential recognition of heat-shock protein dnaJ-derived epitopes by effector and Treg cells leads to modulation of inflammation in juvenile idiopathic arthritis. Arthritis Rheum 56:1648-1657

37. Petty RE, Southwood TR, Manners P, Baum J, Glass DN, Goldenberg J et al (2004) International Leaque of Associations for Rheumatology classification of juvenile idiopathic arthritis: second revision, Edmonton, 2001. J Rheumatol 31:390-392

38. Jabs DA, Nussenblatt RB, Rosenbaum JT (2005) Standardization of uveitis nomenclature for reporting clinical data. Results of the First International Workshop. Am J Ophthalmol 140:509-516

39. Ping L, Duong DM, Yin L, Gearing M, Lah JJ, Levey Al et al (2018) Global quantitative analysis of the human brain proteome in Alzheimer's and Parkinson's Disease. Sci Data 5:180036

40. Wingo TS, Duong DM, Zhou M, Dammer EB, Wu H, Cutler DJ et al (2017) Integrating next-generation genomic sequencing and mass spectrometry to estimate allele-specific protein abundance in human brain. J Proteome Res 16:3336-3347

41. Seyfried NT, Dammer EB, Swarup V, Nandakumar D, Duong DM, Yin L et al (2017) A multi-network approach identifies protein-specific co-expression in asymptomatic and symptomatic Alzheimer's disease. Cell Syst 4(60-72):e4

42. Huang DW, Sherman BT, Lempicki RA (2009) Bioinformatics enrichment tools: paths toward the comprehensive functional analysis of large gene lists. Nucleic Acids Res 37:1-13

43. Huang DW, Sherman BT, Lempicki RA (2009) Systematic and integrative analysis of large gene lists using DAVD bioinformatics resources. Nat Protoc 4:44-57

\section{Submit your manuscript to a SpringerOpen ${ }^{\circ}$ journal and benefit from:}

- Convenient online submission

- Rigorous peer review

- Open access: articles freely available online

- High visibility within the field

- Retaining the copyright to your article

Submit your next manuscript at $\boldsymbol{\nabla}$ springeropen.com 